\title{
Synthesis of $\mathrm{SnSb}_{2} \mathrm{Te}_{4}$ Microplatelets by High-energy Ball Milling
}

\author{
Mário Sérgio da Luz ${ }^{a *}$, Fernando Pacheco Tofanello ${ }^{a}$, Murilo Senhuki Esposto ${ }^{a}$, \\ Ariana de Campos ${ }^{a}$, Bento Ferreira ${ }^{b}$, Carlos Alberto Moreira dos Santos ${ }^{b}$ \\ ${ }^{a}$ Universidade Federal do Triângulo Mineiro - UFTM, Rua Dr. Randolfo Borges Júnior, 1250, \\ CEP 38066-200, Uberaba, MG, Brazil \\ ${ }^{b}$ Escola de Engenharia de Lorena, Universidade de São Paulo - USP, CP 116, \\ CEP 12602-810, Lorena, MG, Brazil
}

Received: November 23, 2014; Revised: August 31, 2015

\begin{abstract}
In this work we demonstrate that high-energy ball milling process can be used to synthesize $\mathrm{SnSb}_{2} \mathrm{Te}_{4}$ without surfactant and further annealing. Milling parameters such as ball to raw material ratio $(5: 1)^{2}$ and milling time (2h) were determined to be suitable for synthesizing microplatelets of $\mathrm{SnSb}_{2} \mathrm{Te}_{4}$. The powders after milling for various durations were characterized by X-ray powder diffraction, scanning electron microscopy and electrical resistance measurements.
\end{abstract}

Keywords: mechanical alloying, semiconductors, electrical properties

\section{Introduction}

Among several alloys with $\mathrm{AB}_{2} \mathrm{X}_{4}(\mathrm{~A}=\mathrm{Ge}, \mathrm{Pb}, \mathrm{Sn}$; $\mathrm{B}=\mathrm{Sb}, \mathrm{Bi}$; and $\mathrm{X}=\mathrm{Se}, \mathrm{Te}$ ) composition, $\mathrm{SnSb}_{2} \mathrm{Te}_{4}$ looks as a promising candidate for various important applications such as phase-change material for non-volatile memory applications or efficient thermoelectric material ${ }^{1-4}$. This compound crystallizes in a layered hexagonal lattice with its large unit cell composed of alternating layers of $\mathrm{Sn}, \mathrm{Sb}$ or Te atoms ${ }^{5}$. $\mathrm{SnSb}_{2} \mathrm{Te}_{4}$ shows a semiconducting behavior and recently has been addressed as a $p$-type topological insulator material ${ }^{6,7}$.

$\mathrm{SnSb}_{2} \mathrm{Te}_{4}$ bulk samples has been synthesized by solid state reaction ${ }^{8}$ or melting of stoichiometric amounts from the elementary reagents ${ }^{9}$. These methods require long processing time, high temperature which are costly. In spite of this, the high-energy ball milling (HEBM) is a simple, inexpensive and efficient method for preparation of powder in bulk amount. This processing technique, also called mechanochemical synthesis, has been already used in the preparation of various materials such as amorphous metallic alloys, composites and also in the modification of different classes of inorganic materials ${ }^{10,11}$.

Based on the mentioned above, this work reports on the HEBM effect in the microplatelets formation from the Sn-Sb-Te powders.

\section{Experimental Procedure}

High purity (99.99\%) Sn, Sb and Te powders were used as precursor material in order to produce the $\mathrm{SnSb}_{2} \mathrm{Te}_{4}$ compound, which were mixed in its stoichiometric ratio. A total approximately of $1 \mathrm{~g}$ of the starting mixture was loaded with Agate balls into a cylindrical Agate vial at room temperature. The ball to mixture weight ratio was approximately $5: 1$. To prevent excessive heating of the vials, the experiments were carried out by alternating $60 \mathrm{~min}$ of milling followed

*e-mail: daluz.mario@icte.uftm.edu.br by $15 \mathrm{~min}$ in standby when the mixture was homogenized. All experiments in air were performed in a SPEX 8000M ball mill. The milling time ranged up to $6 \mathrm{~h}$. Structure and phase identifications were made using X-ray powder diffraction (XRD) (PANalytical model Empyren) using $\mathrm{Cu} \mathrm{K} \alpha$ radiation. Simulations of the $\mathrm{SnSb}_{2} \mathrm{Te}_{4}$ structure and lattice parameters refinement were carried out using Powder Cell software $(\mathrm{PCW})^{12}$, and the crystallographic data ${ }^{5}$ is showed in the Table 1. Morphological characterization and compositional analysis of the samples were made using a scanning electron microscope (SEM) model LEO 1450VP with an Oxford energy dispersive spectrometer (EDS).

Resistance as a function of temperature was measured in a Physical Property Measurement System (PPMS) from Quantum Design using the standard four-probe method. Powder samples to measure the transport properties were densely compacted into a rectangular shape without further annealing.

\section{Results}

Figure 1 shows the $\mathrm{X}$-ray diffraction patterns of $\mathrm{Sn}-\mathrm{Sb}$ - $\mathrm{Te}$ mixtures after milling times from 0 to $6 \mathrm{~h}$. It can be observed that the formation of $\mathrm{SnSb}_{2} \mathrm{Te}_{4}$ with $R-3 m$ hexagonal structure starts after $0.5 \mathrm{~h}$ of milling, and it is complete after $2 \mathrm{~h}$. This is shown by the presence of the sharp peaks corresponding to this phase and indicated by crosses. To confirm this assumption the Figure 1 also shows the simulated XRD for the $\mathrm{SnSb}_{2} \mathrm{Te}_{4}$ phase. An excellent agreement is found between the experimental result and the simulated structure. This indicates that HEBM is adequate to form $\mathrm{SnSb}_{2} \mathrm{Te}_{4}$ powders. Additional minor peaks corresponding to $\mathrm{SnO}_{2}$ were also present (and indicated by asterisk symbol). The XRD pattern of the initial powder reveals the sharp peaks of $\mathrm{Sb}$ and Te phases, while very small peaks related to Sn phase were detected due its low content. 
Despite of $\mathrm{SnSb}_{2} \mathrm{Te}_{4}$ phase can be synthesized with $2 \mathrm{~h}$ of milling, a careful analysis of the diffractograms of Figure 1 indicates displacement of the peaks as a function of milling time, which suggests changes in the lattice parameters. Figure 2 shows the dependence of the lattice parameters as a function of time milling. The result shows weak negative linear dependence of $a$ parameter as a function of milling time. On the other hand, $c$ parameter does not show any

Table 1. Crystal structure parameters of $\mathrm{SnSb}_{2} \mathrm{Te}_{4}$ which crystallizes in a hexagonal cell, space group $R-3 m$ (166), with lattice parameters $a=4.2940 \AA$ and $c=41.5480 \AA^{5}$.

\begin{tabular}{ccccl}
\hline \multirow{2}{*}{ Atom } & \multirow{2}{*}{ Wyckoff Positions } & \multicolumn{3}{c}{ Parameters } \\
\cline { 3 - 5 } & & $\mathbf{x}$ & $\mathbf{y}$ & \multicolumn{1}{c}{$\mathbf{Z}$} \\
\hline $\mathrm{Sn}(1)$ & 3a & 0.00 & 0.00 & 0.00 \\
$\mathrm{Sb}(1)$ & 3a & 0.00 & 0.00 & 0.00 \\
$\mathrm{Sn}(2)$ & 6c & 0.00 & 0.00 & 0.4262 \\
$\mathrm{Sb}(2)$ & 6c & 0.00 & 0.00 & 0.4262 \\
$\mathrm{Te}$ & 6c & 0.00 & 0.00 & 0.133 \\
$\mathrm{Te}$ & 6c & 0.00 & 0.00 & 0.289 \\
\hline
\end{tabular}

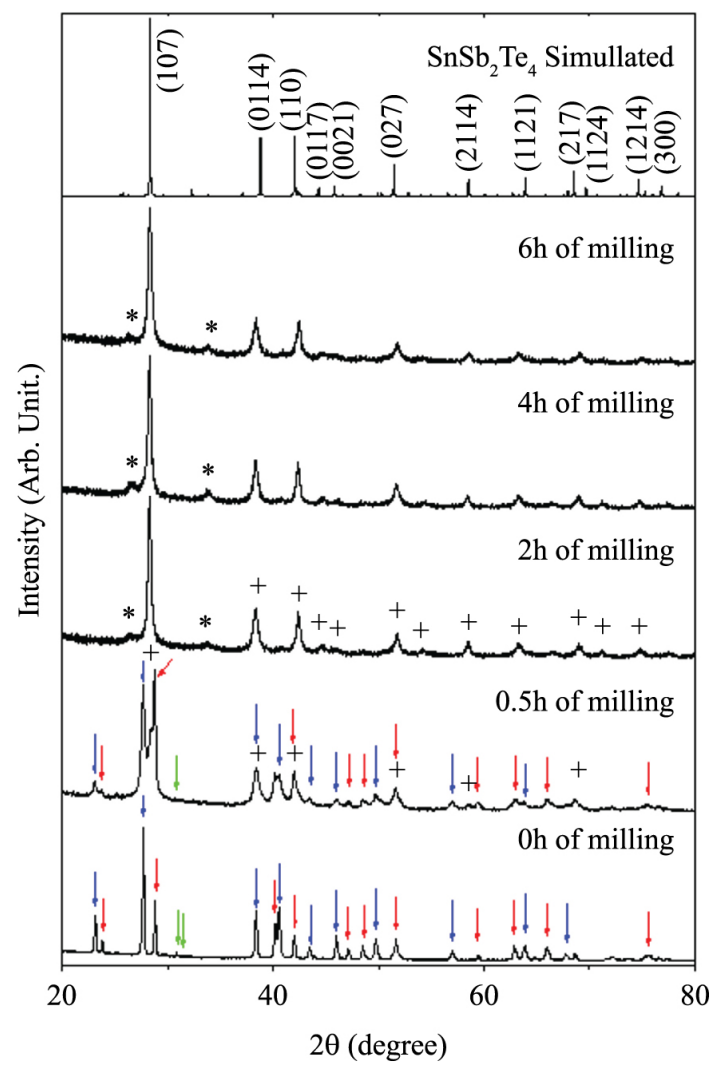

Figure 1. (color online) Structural evolution of the $\mathrm{SnSb}_{2} \mathrm{Te}_{4}$ mixture after milling times for $0,0.5,2,4$ and $6 \mathrm{~h}$. This figure also displays (on top) the simulated diffractogram for $\mathrm{SnSb}_{2} \mathrm{Te}_{4}$ structure by PCW software ${ }^{12}$. All peaks indicated by crosses can be indexed as $\mathrm{SnSb}_{2} \mathrm{Te}_{4}$ reflections and minor peaks corresponding to $\mathrm{SnO}_{2}$ were indicated by asterisk symbol. $\mathrm{Sn}, \mathrm{Sb}$ an Te are indicated by green, red and blue narrows respectively. clear tendency to changing with milling time. The decrease of $a$ parameter with milling time can be attributed to the severe plastic deformation during HEBM which can refine the powder and the lattice strain increases in the system. Corroborating to this, the Figure 2 also show the dependence of the lattice strain with milling time where it can be noted that strain increased continuously with milling time (For this purpose, three diffraction peaks, which had high intensities, were chosen for the measurement and the lattice strain was calculated as T. Ahmadi et al. ${ }^{13}$ ). This can explain the decrease of $a$ parameter with milling time and why this parameter in Figure 2 is smaller than this of Table 1.

Figure 3 shows the details of powders after 6 hours of milling. It can be seen that the high- energy ball milling induces a formation of microplatelets with irregular large sizes and $\sim 7 \mu \mathrm{m}$ in average thickness. Small particles can also be observed probably originated by mechanical cracking during the milling process. The micrographs presented in Figure 3 are representative of powders milled for $2 \mathrm{~h}$ and $4 \mathrm{~h}$ it was also observed microplatelets of $\mathrm{SnSb}_{2} \mathrm{Te}_{4}$. Analysis with EDS pointed to both irregular platelets and the small particles have $\mathrm{SnSb}_{2} \mathrm{Te}_{4}$ composition. For example, Figure 4 shows EDS image performed on the marked particle $(\otimes)$ in the right micrograph of Figure 3. Based on these results, it can be concluded that after $2 \mathrm{~h}$ of milling the time does not affect the formation of $\mathrm{SnSb}_{2} \mathrm{Te}_{4}$ microplatelets.

The electrical transport properties of as-milled $(6 \mathrm{~h})$ and compacted powders are presented in Figure 5, which shows the temperature dependence on the electrical resistance. It is possible to observe a semiconducting behavior, as expected for samples of $\mathrm{SnSb}_{2} \mathrm{Te}_{4}$. Similar behavior was also observed in other milled samples. The results of Figures 1 to 5 combine, confirm that HEBM is a very effective method to produce powders with $\mathrm{SnSb}_{2} \mathrm{Te}_{4}$ composition.

Finally, a possible mechanism of $\mathrm{SnSb}_{2} \mathrm{Te}_{4}$ formation during ball milling is based on an exothermic reaction. We suggest that during milling, the collisions between the milling balls and the vial walls serve as the ignition mechanism and may trigger reactions at some local hot spots. This supposition can explain the very short time $(2 \mathrm{~h})$ needed to obtain the complete formation of $\mathrm{SnSb}_{2} \mathrm{Te}_{4}$ phase.

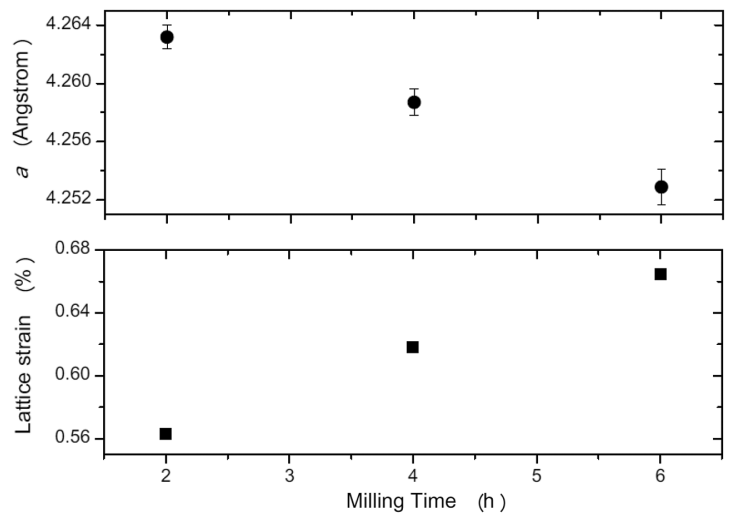

Figure 2. Variation of $a$ lattice parameter and lattice strain of the obtained powders vs. milling times. 


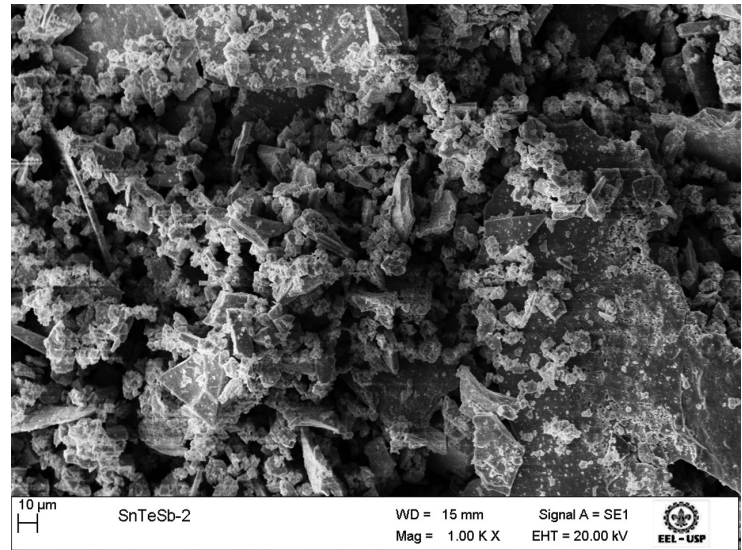

(a)

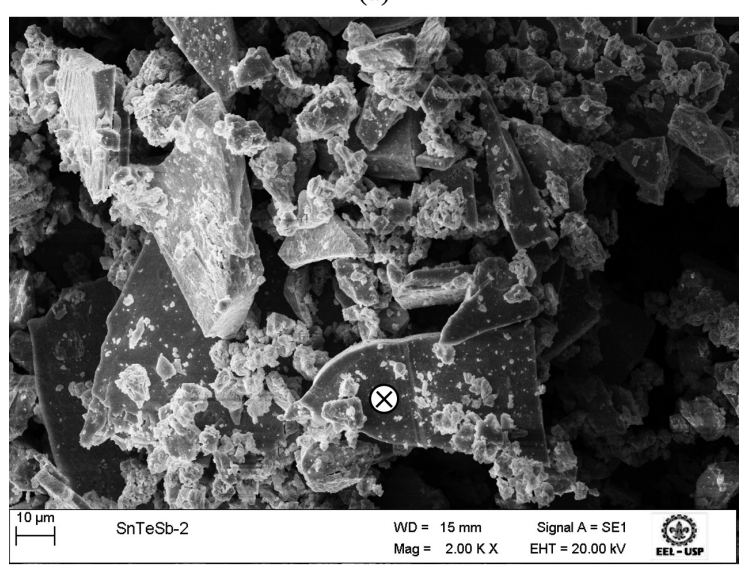

(b)

Figure 3. Details of $\mathrm{SnSb}_{2} \mathrm{Te}_{4}$ powders after 4 hours of milling.

\section{Conclusion}

$\mathrm{SnSb}_{2} \mathrm{Te}_{4}$-based microplatelets were successfully synthesized via mechanochemical activation using $2 \mathrm{~h}$ high-energy ball milling in air. It was observed by X-ray diffraction that severe plastic deformation decrease the $a$ lattice parameter as a function of milling time which can be associated with structural disorder induced by milling.

\section{References}

1. Wuttig M and Yamada N. Phase-change materials for rewriteable data storage. Nature Materials. 2007; 6(11):824-832. http:// dx.doi.org/10.1038/nmat2009. PMid:17972937.

2. Lencer D, Salinga M, Grabowski B, Hickel T, Neugebauer $\mathrm{J}$ and Wuttig M. A map for phase-change materials. Nature Materials. 2008; 7(12):972-977. http://dx.doi.org/10.1038/ nmat2330. PMid:19011618.

3. Frumar M, Frumarova B, Wagner T and Hrdlicka M. Phase change memory materials-composition, structure, and properties. Journal of Materials Science Materials in Electronics. 2007; 18(S1):S169-S174. http://dx.doi.org/10.1007/s10854-0079187-7.

4. Welzmiller S, Rosenthal T, Ganter P, Neudert L, Fahrnbauer F, Urban P, et al. Layered germanium tin antimony tellurides: element distribution, nanostructures and thermoelectric properties.

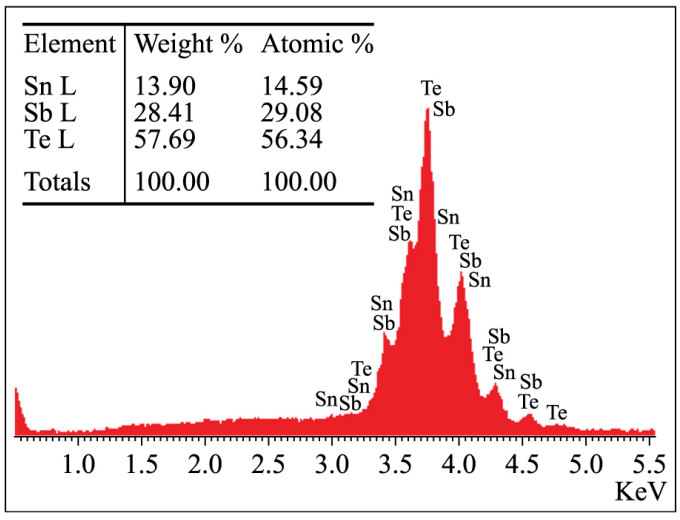

Figure 4. (color online) EDS results of chemical composition point $\otimes$ in the right picture of Figure 3. The inset shows the microanalysis data of $\mathrm{SnSb}_{2} \mathrm{Te}_{4}$ microplatelets after 4 hours of milling.

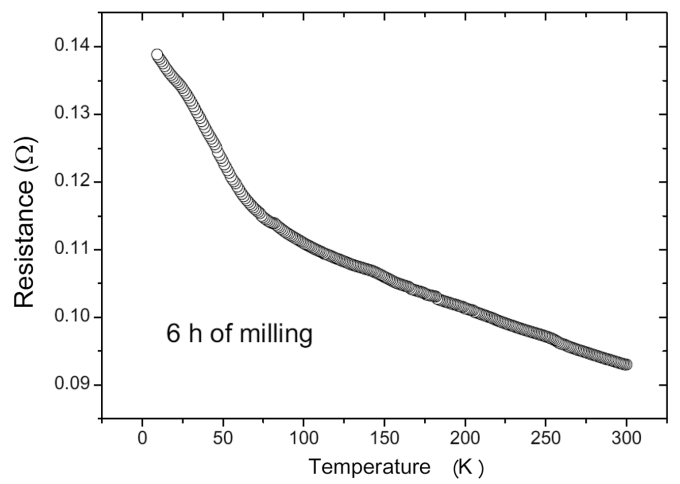

Figure 5. Resistance as a function of temperature of as-milled (6 h) and compacted powders.

Based on these results the HEBM was extremely efficient to form the $\mathrm{SnSb}_{2} \mathrm{Te}_{4}$ compound from the elemental powders.

\section{Acknowledgements}

This material is based upon work supported by the $\mathrm{CNPq}$ (448041/2014-6, 300821/2012-3), FAPEMIG, FUNEPU, and FAPESP (2009/54001-2). We also like to thanks A. J. S. Machado and L. E. Corrêa for experimental support.

Dalton Transactions. 2014; 43(27):10529-10540. http://dx.doi. org/10.1039/C4DT00336E. PMid:24681809.

5. Zhukova TB and Zaslavskii AI. Crystal structures of compounds $\mathrm{PbBi}_{4} \mathrm{Te}, \mathrm{PbBi}_{2} \mathrm{Te}_{4}, \mathrm{SnBi}_{4} \mathrm{Te}_{7}, \mathrm{SnBi}_{2} \mathrm{Te}_{4}, \mathrm{SnSb}_{2} \mathrm{Te}_{4}$, and $\mathrm{GeBi}_{4} \mathrm{Te}_{7}$. Soviet Physics, Crystallography. 1972; 16:796-800.

6. Concas G, Pascale TM, Garbato L, Ledda F, Meloni F, Rucci A, et al. Electronic and structural-properties of the layered $\mathrm{SnSb}_{2} \mathrm{Te}_{4}$ semiconductor-abinito total-energy and mossbauerspectroscopy study. Journal of Physics and Chemistry of Solids. 1992; 53(6):791-796. http://dx.doi.org/10.1016/00223697(92)90191-F.

7. Niesner D, Otto S, Hermann V, Fauster T, Menshchikova TV, Eremeev SV, et al. Bulk and surface electron dynamics in a p-type topological insulator SnSb2Te4. Physical Review B. 2014; 89(8):081404(R). 
8. Goncharuk LV and Sidorko VR. Thermodynamic properties of SnSb2Te4 ternary compounds. Powder Metallurgy and Metal Ceramics.1998; 37(11-12):638-640.

9. Oeckler O, Schneider MN, Fahrnbauer F and Vaughan G. Atom distribution in $\mathrm{SnSb}_{2} \mathrm{Te}_{4}$ by resonant $\mathrm{X}$-ray diffraction. Solid State Sciences. 2011; 13(5):1157-1161. http://dx.doi. org/10.1016/j.solidstatesciences.2010.12.043.

10. Suryanarayana C. Mechanical alloying and milling. Progress in Materials Science. 2001; 46(1-2):1-184. http://dx.doi. org/10.1016/S0079-6425(99)00010-9.

11. Luz MS, Ferreira A, Campos A, Corrêa LE and Machado AJS. Synthesis of $\mathrm{HgPb} 2$ assisted by high energy ball milling.
Materials Research Innovations. 2015; 19(2):129-132. http:// dx.doi.org/10.1179/1433075X14Y.0000000228.

12. Kraus W and Nolze G. POWDER CELL - a program for the representation and manipulation of crystal structures and calculation of the resulting X-ray powder patterns. Journal of Applied Crystallography. 1996; 29(3):301-303. http://dx.doi. org/10.1107/S0021889895014920.

13. Ahmadi T, Monshi A, Mortazavi V, Fathi MH, Sharifi S, Hashemi Beni B, et al. Synthesis and dissolution behavior of nanosized silicon and magnesium co-doped fluorapatite obtained by high energy ball milling. Ceramics International. 2014; 40(6):83418349. http://dx.doi.org/10.1016/j.ceramint.2014.01.040. 